\title{
A comparison of the species-time relationship across ecosystems and taxonomic groups
}

\author{
Ethan P. White, Peter B. Adler, William K. Lauenroth, Richard A. Gill, David \\ Greenberg, Dawn M. Kaufman, Andrew Rassweiler, James A. Rusak, Melinda D. \\ Smith, John R. Steinbeck, Robert B. Waide, and Jin Yao
}

E. P. White and R. B. Waide, Department of Biology, University of New Mexico, Albuquerque, NM 87131 (epwhite@unm.edu).-P. B. Adler, D. Greenberg, and A. Rassweiler, Department of Ecology, Evolution and Marine Biology, University of California, Santa Barbara, CA 93106. W. K. Lauenroth, Department of Forest, Rangeland, and Watershed Stewardship, Colorado State University, Fort Collins, CO 80523. - R. A. Gill, Program in Environmental Science and Regional Planning, Washington State University, Pullman, WA 99164. - D. M. Kaufman, Division of Biology, Kansas State University, Manhattan, KS 66506. - J. A. Rusak, Center for Limnology, University of Wisconsin - Madison, Trout Lake Station, Boulder Junction, WI 54512. - M. D. Smith, Yale University, Department of Ecology and Evolutionary Biology, New Haven, CT 06520. - J. R. Steinbeck, Tenera Environmental, 225 Prado Rd., Suite D, San Luis Obispo, CA 93401. - J. Yao, USDA ARS Jornada Experimental Range, Las Cruces, NM 88003.

Current address for correspondence: Ethan White, Utah State University, 5305 Old Main Hill, Logan, UT, 84321, USA. Email: epwhite@,biology.usu.edu. Phone: 435-760-1909. Fax: 435797-2485.

Abstract: The species-time relationship (STR) describes how the species richness of a community increases with the time span over which the community is observed. This pattern has numerous implications for both theory and conservation in much the same way as the speciesarea relationship (SAR). However, the STR has received much less attention and to date only a handful of papers have been published on the pattern. Here we gather together 984 community time-series, representing 15 study areas and 9 taxonomic groups, and evaluate their STRs in order to assess the generality of the STR, its consistency across ecosystems and taxonomic groups, its functional form, and its relationship to local species richness. In general, STRs were surprisingly similar across major taxonomic groups and ecosystem types. STRs tended to be well fit by both power and logarithmic functions, and power function exponents typically ranged between 0.2 and 0.4. Communities with high richness tended to have lower STR exponents, suggesting that factors increasing richness may simultaneously decrease turnover in ecological systems. Our results suggest that the STR is as fundamental an ecological pattern as the SAR, and raise questions about the general processes underlying this pattern. They also highlight the dynamic nature of most species assemblages, and the need to incorporate time scale in both basic and applied research on species richness patterns.

Key words: species-time relationship; temporal turnover; temporal dynamics; species richness; species-area relationship 


\section{Introduction}

An important challenge for ecologists is to understand the causes and consequences of species diversity. The first step in addressing this challenge is documenting species richness in different ecosystems. These data are necessary to study patterns such as the latitudinal gradient in species richness and the productivity-diversity relationship, and are relied upon by conservation biologists to prioritize areas for conservation. However, as illustrated by the species-area relationship, estimates of species richness are dependent on the scale of observation, and conclusions based on analyses conducted at one scale may not be directly applicable at other scales (e.g. Levin 1992, Milne 1992, Rahbek and Graves 2001, Chase and Leibold 2002, Chalcraft, et al. 2004).

The species-area relationship (SAR) describes the dependence of species richness on spatial scale: as the area sampled increases, the number of species observed also increases. This pattern tends to be well described by both power and logarithmic functions (e.g. Connor and McCoy 1979, Rosenzweig 1995, Lennon, et al. 2001). The observed form of the SAR is of interest because it suggests that in general species are distributed in a characteristic non-random pattern across the landscape. Theoretical attempts to explain this pattern have invoked environmental heterogeneity (Williams 1964, Harner and Harper 1976), local dispersal (Plotkin, et al. 2000), population dynamics (Wissel and Maier 1992), niche-based interactions (Shmida and Wilson 1985), self-similarity (Harte, et al. 1999, Sizling and Storch 2004), and neutral theory (Bell 2001, Hubbell 2001). Conservation ecologists use the SAR to scale-up field estimates of species richness in an attempt to identify diversity hot-spots (Myers, et al. 2000) and to make predictions about extinction following habitat loss (Pimm and Askins 1995, Brooks, et al. 1997).

In contrast, the species-time relationship (STR), the temporal analogue of the SAR, has received little attention. The STR describes the increase in the number of species recorded at a site as that site is observed for increasingly long periods of time (Grinnell 1922, Preston 1960, Rosenzweig 1995). The limited evidence available suggests that STRs are well fit by power functions for mammals (Hadly and Maurer 2001) and plants (Adler and Lauenroth 2003) and by logarithmic functions for insects (Rosenzweig 1995) and birds (White 2004). This increase in species richness is likely driven by a combination of random-sampling processes at short time scales and ecological processes such as climatic variability, successional changes, and metapopulation dynamics at longer time scales (Preston 1960, Rosenzweig 1995, Adler and Lauenroth 2003, White 2004).

Adding an understanding of the relationship between time span and species richness to our knowledge about the relationship between spatial scale and richness has important implications for both theory and application. For example, taking into account the relationship between spatial and temporal patterns may allow researchers to support or rule out candidate mechanisms for poorly understood patterns such as the SAR. Adler (2004) showed that while neutral models could reproduce realistic patterns for either the SAR or the STR, these models failed when trying to generate both patterns simultaneously. On the applied side, conservation priorities or predictions of species loss will depend on the temporal as well as the spatial scale of sampling when estimates of species richness prove sensitive to the time span of observation.

Despite the potential importance of the STR for ecological theory and conservation applications, empirical information on this pattern remains extremely limited. Our objectives for this manuscript are to evaluate the generality of the STR, to assess its consistency across ecosystems and taxonomic groups, to determine whether there are important differences between 
the fits of power and logarithmic functions to observed STRs, and to evaluate how the slope of the linearized STR, a measure of temporal turnover, depends on species richness.

\section{Methods and Background}

We used data from 15 sites and 9 taxonomic groups to calculate a total of 984 species-time relationships (Table 1, Appendix A). This includes 521 previously published species-time relationships for North American land birds (White 2004), calculated using Breeding Bird Survey (BBS) routes. Each route represents a unique site; however, for the purpose of comparison within and between taxonomic groups we treated the BBS as a single site to prevent it from dominating analyses. We excluded the BBS data from ecosystem comparisons.

\section{Functional form of the STR}

Similar to the SAR, the STR has typically been fit using either power functions, of the form $S=c T^{w}$, or logarithmic functions such as $S=c+w \log T$, where $c$ is a constant that approximates the observed species richness $(S)$ at some characteristic time-scale (in this case, one year), and $w$ is the slope of the linearized STR on appropriately log-transformed axes (Rosenzweig 1995, White 2004). Although the difference in the fit of these two functions is typically small, and in some cases difficult to distinguish even when the real function is known (McGill 2003), the two functions have different implications for how community composition changes over time and thus could point toward different underlying processes. Power functions imply a constant percentage increase in species richness with each multiplicative increase in time scale, whereas logarithmic functions imply a constant absolute increase. Traditional measures of turnover are almost invariably relative measures (see Koleff, et al. 2003) because most ecologists agree that a single species change represents something very different in a community of 5 species than it does in a community of 50 (e.g., Russell 1998). Thus it seems that the power exponent is a more appropriate choice for comparing taxa and ecosystems. However, if a logarithmic function provides a better fit to a STR, it is possible to calculate a relative measure of species addition rate by dividing the slope by the mean annual richness. This measure would represent the number of species added for each order of magnitude increase in scale as a percentage of the number occurring at the minimum scale (or any other reference scale; in our case a single year). For our datasets, the power function exponent and this standardized logarithmic function slope were highly correlated $(r=0.97)$.

\section{Constructing STRs}

The first step in constructing a species-time relationship is to estimate the number of species found in a given time span of observation. We used a moving window approach where species richness was determined for every possible window of each time span (e.g., in a 20 year time series, 20 one-year windows, 19 two-year windows, etc.). These values were then averaged within each time span (we used arithmetic means, but using geometric means did not affect the results). Next, we fit the two statistical models (power and logarithmic functions) to these averages using two methods: ordinary least squares regression (OLS) on log-transformed data and non-linear regression on untransformed data. For the non-linear fitting we used the parameter estimates from the OLS as the initial parameter values. OLS and non-linear fitting produced nearly identical parameter estimates (Pearson's $r \geq 0.99$ for both functions). We compared fits of the non-linear power and logarithmic regressions using $r^{2}$ values (because there are 2 parameters in both models there is no need for more complex model comparison 
techniques).

\section{The influence of sampling on the STR}

There are two potential explanations for observed increases in species richness with time span: 1) increased sampling from a static pool of species; and 2) non-random changes in the species composition at a site through time. Mounting evidence in the literature suggests that the accumulation of richness through time in natural systems is not purely the result of sampling, but rather reflects the non-random distribution of species through time (Rosenzweig 1995, Rosenzweig 1998, McKinney and Frederick 1999, Hadly and Maurer 2001, Adler and Lauenroth 2003, White 2004). However, to confirm that we were not analyzing patterns driven purely by sampling more individuals, we also compared the observed STRs from a subset of our datasets (those containing abundance estimates; Table 1) to a random sampling model originally developed for the SAR, $S(T)=S_{0}-\sum_{i=1}^{S_{0}}\left(1-T / T_{0}\right)^{n_{i}}$, where $S(T)$ is the expected number of species occurring over time span $T$, when $S_{0}$ species and $n_{\mathrm{i}}$ individuals of the ith species were observed over the entire $T_{0}$ years of the time series (Arrhenius 1921, Coleman 1981, White 2004). An increase in $S$ due to sampling can result from either incomplete sampling of the community of interest by the observer, or random year-to-year assembly of that community from a static pool. This model generates the expected STR for a given abundance distribution if individuals were distributed randomly in time, and as such focuses on the random year-to-year assembly aspect of sampling.

We also used this subset to fit two recently proposed two-phase models that combine the random sampling model with either the power or logarithmic statistical models. These two-phase models allow us to estimate the time scale at which ecological changes become relatively more important than random-sampling effects by fitting the sampling model to short time scales, the statistical models to long time scales, and choosing the transition point between the sampling and statistical models so as to minimize the residual sums of squares (RSS) of the overall model (for detailed methods see White 2004). We compared the fits of all five models (power, logarithmic, two-phase power, two-phase logarithmic, and sampling) using Akaike's Information Criteria (AIC) with 0 free parameters for the sampling model, which is completely constrained by the observed vector of species abundances, 2 parameters for the power and logarithmic models, and 3 parameters for the two-phase models (e.g., Burnham and Anderson 1998, Venables and Ripley 1999). Because the data points in STRs are not independent, the AIC comparison provides only an arbitrary penalty for the inclusion of additional parameters. We also compared models using a standard correction to the RSS for different numbers of parameters, $k$ (RSS/ $[n-2 k]$; Efron and Tibshirani [1993], Hilborn and Mangel [1997]). The two approaches produced similar results (we report results using AIC).

\section{Temporal turnover and species richness}

The slope of the linearized STR can be considered a measure of temporal turnover (Rosenzweig 1998, White 2004) in the same way that the slope of the SAR is considered a measure of spatial turnover (e.g., Harte and Kinzig 1997, Lennon, et al. 2001, Koleff, et al. 2003). Two contrasting patterns have been observed between local richness and spatial turnover: 1) positive relationships, where high richness sites have high spatial turnover (Kaufman 1998, Clarke and Lidgard 2000, Stevens and Willig 2002), and 2) negative relationships, where high richness sites have low spatial turnover (Lennon, et al. 2001, Lyons and Willig 2002, Koleff, et al. 2003). The 
one study which explored this relationship for temporal turnover found a negative relationship with mean annual richness (White 2004). We note that because most measures of turnover are relative a negative relationship between turnover and richness is expected to occur if the absolute rate of species addition increases less than linearly with species richness.

We assessed relationships between the slope of the linearized STR and mean annual species richness, $\bar{S}$, both within sites and taxa and across sites and taxa using OLS regression on log-transformed variables. Mean annual species richness is defined as the average number of species occurring in a single year. The cross-site, cross-taxa relationship was evaluated using the average values of $\bar{S}$ and $w$ for each site-taxon combination. We treated the Breeding Bird Survey datasets as a single point to prevent them from dominating the pattern; excluding BBS data did not affect the results.

\section{Results}

\section{Functional Form}

We constructed 984 STRs representing a variety of taxa and ecosystems all of which were fit well by either power or logarithmic functions. For 512 STRs, the power function had the highest $r^{2}$, with the other 472 relationships better fit by the logarithmic function. However, the differences in $\mathrm{r}^{2}$ between the two functions were small (range -0.05 to 0.13 ) and the median of the distribution of $r^{2}$ s was not significantly different from zero $(P=0.66$; 1 -sample sign test; Fig. 1). Despite the small size of the differences between the two functional forms of the STR, there were distinctive patterns within particular taxonomic groups. Across taxa, the power function was favored for corals (8 of 8 STRs) and for all vascular plants (141 of 164). For the remaining taxa, neither the power nor the logarithmic function consistently provided the best fit: for grasshoppers, the power function fit two STRs, while the logarithmic function best described one. For fish, the split was even (12 and 12), while for zooplankton ( 3 and 4), birds (267 and 321 ), intertidal invertebrates (31 and 49), benthic algae (38 and 47) and mammals (10 and 15) the logarithmic function provided the best fit slightly more often.

For all STRs to which sampling models were fit, the sampling model was never the best description of the data. When combining sampling and statistical models into two-phase relationships, most taxa and locations transitioned from sampling to non-sampling phases quite quickly. Non-BBS systems, excluding Fort Riley, transitioned at approximately 3 years (median value for the $80 \%$ of communities that were better fit by two-phase models) and BBS sites transitioned at approximately 2 to 3 years (Fig.2). The Fort Riley STRs, on the other hand, did not transition until approximately seven years (median value for the $83 \%$ of relationships that were better fit by a two-phase model). Since the Fort Riley time series are at most 11 years long, this means that the majority of the points in the Fort Riley STRs are determined predominantly by random sampling of the relative abundance distribution of the community, not by temporal ecological changes (Fig. 2). For the majority of communities, incorporating the sampling phase of the relationship did not in general change which statistical function best fit the data. For example, if the data were best fit by a power function using standard fitting, they were most often best fit by either a power function or a sampling-power function using two-phase fitting.

Because the two statistical functions are so similar, and the power function exponent provides an inherently relative measure of turnover (see Methods), we have chosen to use only the exponents from the power function in our analyses of cross-site, cross-taxonomic, and richness-turnover patterns. 


\section{Cross-site and cross-taxonomic comparisons}

Averaging STRs by study area and taxon yielded mean power function exponents ranging from 0.10 to 0.52 (Fig. 3, Appendix B). There was notable clustering of exponents within and among taxa. Average exponents for taxonomic groups ranged from 0.23 to 0.39 (means of study area means; Fig. 3, dotted lines). The invertebrate groups (grasshoppers, intertidal invertebrates, corals, and zooplankton) had a fairly narrow range of means (0.23-0.37), even though they represent a wide variety of life histories and ecosystems. The vertebrates (fish, birds, and mammals) were remarkably similar, ranging only from 0.23 to 0.26 in average STR exponent. However, the two autotroph groups appeared to cluster differently, with land plant site averages ranging from 0.32 to 0.46 and algae averages ranging from 0.21 to 0.30 , despite very similar sampling designs. Birds were the group with the highest variability in individual sample exponents (from less than 0.10 to more than 0.60 ). However, this variability was driven in part by the extremely high values for Fort Riley, which likely resulted from the large influence of sampling on their STRs (see Functional Form). Taking the mean STR for each study area and taxon and averaging them by ecosystem type produced similarly constrained average exponents (Fig. 3 inset). All of the mean ecosystem STR exponents fell between 0.10 and 0.38 . Forests had the lowest exponents (though this ecosystem type was represented only by a single bird community) and grasslands and coral reefs the highest.

\section{Temporal turnover and species-richness}

Grouping individual STRs by study area and taxon allowed us to calculate relationships between the exponent of the STR and the mean annual species richness for 20 of 22 groups (the other 2 groups contained only a single point). For these 20 groups, when a significant $(\mathrm{P}<0.05)$ or marginally significant $(\mathrm{P}<0.1)$ relationship existed $(n=8$ and $n=1$ respectively) it was consistently negative (Fig. 4; Appendix B). In 11 of 20 assemblages there was not a significant relationship between turnover and richness $(\mathrm{P}>0.05)$. Small sample sizes may have reduced our ability to detect significant relationships for some of these groups. However, there were two cases in which the sample sizes of these non-significant results were reasonably high (Fort Riley birds and Hays plants; Appendix B). While Fort Riley birds may not exhibit this pattern due to the large influence of sampling processes on their STRs, the exception of the Hays plants suggests that the negative relationship between STR exponent and species richness within sites is not ubiquitous. The cross-site, cross-taxa relationship between $w$ and $\bar{S}$ was significantly negative $\left(w \approx 0.57 \bar{S}^{-0.29} ; \mathrm{P}=0.003\right.$; Fig. 4 inset $)$.

\section{Discussion}

Our overarching goal for this synthesis was to evaluate the generality of the STR. The 984 STRs that we constructed, for a wide range of taxa and ecosystem types, showed rapid accumulation of species with increasing time spans of observation. On average, the observed species richness at a site over a ten year period was almost double that observed in a single year. Beyond a time-span of 2-4 years, sampling processes were rarely the dominant cause of this increase, though the Fort Riley results suggest that in rare cases random-sampling processes may dominate observed STRs (Fig. 2). In general, these results illustrate the ubiquity of the relationship and suggest that the STR deserves to be widely appreciated as a fundamental ecological pattern. The next logical step is to take a more detailed look at its behavior. 


\section{Functional Form}

While the power function best described the STRs of corals and vascular plants, uncertainty about model selection was common in most of our datasets. Power and logarithmic functions were chosen in roughly equal proportions, and overall neither function provided a significantly better fit to the data (Fig. 1). Both functions are extremely flexible, and our analysis confirms that curve fitting is a poor method for identifying the processes underlying STRs (McGill 2003). Despite the similar fits of power and logarithmic models over the observed time scales, model choice could have important consequences if the predictions of the two models diverge when extrapolated beyond the domain of the observed data (Rosenzweig 1995), as is often required in conservation applications of SARs (Pimm and Askins 1995, Myers, et al. 2000). We explored this possibility by using both functions to predict species number at time spans 100 years longer than the observed time series for each of our 984 STRs. In most cases, predicted species numbers differed by less than 5\% (Median difference $=1.96 \%$ ). Thus, even when STRs are extrapolated to predict species numbers for longer time periods, model choice should have little effect on predictions.

In addition to power and logarithmic functions a number of other statistical and process based models have been suggested for describing the SAR (e.g., He and Legendre 1996, Lomolino 2000, Ovaskainen and Hanski 2003, Sizling and Storch 2004) and equivalent temporal models may also do a good job of describing observed STRs. Instead of using comparisons of different functions in an attempt to infer underlying processes, a better understanding of processes should dictate model choice. This will require new approaches for testing the relative importance of temporal habitat heterogeneity, metapopulation dynamics, and other potential mechanisms responsible for generating this common pattern. Nevertheless, while many different functions may do a good job of describing the data, the power law is especially useful for comparative work because its exponent provides a simple measure of relative species turnover.

Cross-site-taxon comparisons and the relationship between turnover and richness Perhaps the most interesting characteristic of the species-area relationship is that it tends to have similar exponents across locations and taxonomic groups. Power function fits to the SAR typically produce intra-continental exponents between 0.1 and 0.3 (e.g. Connor and McCoy 1979, Rosenzweig 1995), regardless of location or taxonomic group. However, until now no extensive comparisons among taxa and locations existed for the species-time relationship.

Exponents of our STRs generally fell between 0.2 and 0.4 , indicating the kind of regularity that has made the species-area relationship a major focus of ecological research. This observed regularity is somewhat surprising given the methodological heterogeneity among these datasets. The diverse sampling methodologies included complete censusing of plants, Sherman trapping of small mammals, and seining of fish. In addition, the spatial scale of sampling ranged from single $\mathrm{m}^{2}$ plots to BBS survey routes $40 \mathrm{~km}$ in length. In addition to the observed regularity in the exponent of the STR, there remains substantial variability both within and among different sites and taxonomic groups. Finding patterns in this variability should provide us with a better understanding of the processes generating the STR.

A major factor describing this variability appears to be mean annual species richness. In approximately half of our datasets we observed a decrease in temporal turnover with increasing local richness, similar to results from some spatial studies (e.g., Lennon, et al. 2001, Lyons and Willig 2002). In addition, there was a strong negative relationship between turnover and richness 
that explained $37 \%$ of the observed variability across sites and taxonomic groups. The existence of these negative correlations between richness and turnover suggest that in many systems external factors influence richness and turnover in opposite directions.

One external factor that could influence both local species richness and temporal turnover is environmental heterogeneity. Large temporal fluctuations in the environment might cause species to be more temporally patchy in their occurrence, which should lower local species richness and increase temporal turnover. The plant data offer some support for this hypothesis, with the dryer, more variable sites (Jornada and Hays) having both lower species richness and higher turnover than the wetter, less variable sites (Utah and Konza). However, patchiness can also result from biological processes such as local dispersal in space (e.g., Plotkin, et al. 2000, Plotkin, et al. 2002) or long-lived life stages in time. In general, any process that affects intraspecific aggregation, and therefore patchiness, will tend to generate negative correlations between richness and turnover (He and Legendre 2002, Plotkin and Muller-Landau 2002, Veech, et al. 2003, Veech 2005).

The exponent of the STR is also known to be correlated with the spatial scale of analysis, with the exponent decreasing as the scale of observation increases (Adler and Lauenroth 2003). We analysed a subset of our data that include both spatial and temporal information and found relationships that reinforced this idea that estimates of species turnover are dependent on the spatial and temporal scales of sampling (Adler et al. in press). This species-time-area relationship suggests that sites sampled at broader spatial scales should have lower STR exponents, regardless of other causes of variation. Spatial scale cannot explain the negative richnessturnover relationships that we observed within individual study areas, because all STRs within a study area are based on data collected at the same scale. But spatial scale does have the potential to affect cross-site comparisons. For example, plant communities sampled at $1-\mathrm{m}^{2}$ had higher turnover than small mammal communities sampled at scales on the order of hectares. However, such cross-site comparisons are complicated because of three interconnected correlations: 1) the negative relationship between temporal turnover and richness that we have demonstrated, 2) a negative relationship between temporal turnover and spatial scale (Adler and Lauenroth 2003, Adler et al. in press), and 3) a positive relationship between spatial scale and richness, described by the classic SAR. Thus, for cross-site analyses it is unclear whether richness or area is the proximate mechanism depressing temporal turnover. Unfortunately, heterogeneity among our datasets prevents us from disentangling these two processes.

Within sites, differences in sampling scale cannot explain the correlations between richness and turnover, and differences in temporal environmental heterogeneity are also unlikely to explain these patterns since plots in relatively close proximity probably experience similar temporal variability. Therefore, while the within-site pattern implies that some mechanism may influence species richness and turnover in opposite directions, the underlying process remains unclear. One potential explanation is that some locations within a site may be generally more favorable than other locations. If more favorable sites (e.g., those with higher productivity) tend to support the relatively constant occurrence of many species, and less favorable sites tend to support fewer, more ephemeral species, this could result in the observed correlation between richness and turnover. It is also possible that spatial context may be important for understanding patterns of turnover, because the degree of isolation of a site should be related to both its species richness and the number of successful colonizations. Finally, the fact that some sites lacked a significant richness-turnover relationship suggests that the underlying processes may be sitespecific. Attempts to understand these within-site patterns will provide valuable information 
regarding the processes underlying temporal turnover.

While some differences between communities are expected to affect both species richness and turnover, others, such as differences in life history among taxonomic groups, might be expected to primarily influence turnover. One pattern that suggests that life history could have important impacts on the STR is the difference between corals and vascular plants, which were almost always best fit by power functions, and the other taxonomic groups, which were equally well fit by both power and logarithmic functions. This contrast is intriguing because of the obvious difference in life history between these groups: corals and vascular plants are sessile, space-filling organisms, whereas many of the other taxa are mobile. The implication is that life history traits such as dispersal mode and potential for dormancy may be important in allowing a community to track temporal variation in the environment.

Regardless of the processes underlying temporal turnover, a negative relationship between turnover and richness could have important implications for conservation, especially when estimates of richness are used to set conservation priorities. The rank of communities with respect to species richness (and the relationships between richness and environmental variables) can change as a function of spatial scale (e.g. Scheiner, et al. 2000, Rahbek and Graves 2001, Chase and Leibold 2002, Willig, et al. 2003). A negative relationship between richness and turnover means that communities supporting low mean annual richness are likely to have high species turnover and thus could be important to a larger number of species over a longer time span (see also Scheiner, et al. 2000). However, this possibility must be considered with caution, because 1) it is dependent on the power function, not the logarithmic function, being the appropriate description of the STR at larger temporal scales; and 2) because changes in the ranks of species richness for a pair of communities may not occur within relevant ecological time scales.

\section{Conclusions}

Our analyses produced three key results: 1) a remarkable degree of regularity in the STR among ecosystems and taxonomic groups; 2) practically no difference in fit of the two proposed functional forms of the relationship; and 3) a negative relationship between the STR exponent and mean annual richness. Furthering our understanding of these patterns will require more rigorous analyses of less heterogeneous data. We see two possible avenues for this kind of research: 1) the design of studies with standardized methods for collecting time-series across sites; and 2) utilizing subsets of available time-series in which key aspects of the sampling design are the same (e.g., censuses of $1-\mathrm{m}^{2}$ quadrats commonly used for herbaceous plants and other small sessile organisms).

The most important contribution of this work to our understanding of the causes and consequences of species diversity is the clear demonstration that species richness depends on the time span of observation, as well as the size of the area sampled. This means that species richness cannot be reliably compared across sites or ecosystems without information about both the temporal and spatial scale of sampling (Rosenzweig 1995, Adler and Lauenroth 2003). Although the importance of area is widely recognized, acknowledging the role of time will mean that in cross-site comparisons of species richness researchers will need to correct their richness estimates to a single time-scale in the same manner that these studies correct their diversity estimates to a single spatial scale (e.g., Inouye 1998, Gross, et al. 2000, Scheiner, et al. 2000). In addition, our analyses of a subset of the data used in this paper suggest that the SAR and the STR are not independent relationships, but are components of a unified species-time-area relationship 
(Adler et al. in press). This means that we need information on both spatial and temporal scale in order to effectively compare patterns of species turnover as well as patterns of species richness.

Our results emphasize that species assemblages are temporally dynamic (e.g., Diamond 1969, Williamson 1987, Russell, et al. 1995, Russell 1998). This observation is certainly not novel, but it poses a set of difficult challenges for conservation. For example, how long can reserves ensure the conservation of any species, given a constant background level of local extinction events, and what does restoration mean if communities turnover rapidly? It may be that linking temporal turnover with spatial source/sink dynamics provides an even stronger rationale for networks of reserves rather than isolated parks. Understanding species-time relationships will bring us closer to answering these questions, and will aid in our understanding of the dynamic nature of ecological systems.

Acknowledgements - This work was conducted as part of the Species Richness in Space and Time Workshop funded by the LTER Network Office under Cooperative Agreement No. DEB0236154 between NSF and the University of New Mexico. We thank the following for constructive conversation and/or comments on a previous version of the ms: B.T. Milne, S.K.M. Ernest, E.L. Charnov, A.H. Hurlbert, D. Storch, J.H. Brown, and three anonymous reviewers. We thank the following people and institutions for contributing data: J.H. Brown, S. Collins, J.H. Connell, E.W. Evans, D. Gibson, P. Henderson, D.W. Kaufman, G.A. Kaufman, J. Rivers, J. Schaefer, G. Towne, J.L. Zimmerman, BBS volunteers and USGS/ CWS researchers and managers, Pacific Gas \& Electric Co., the Portal LTREB, the U.S. Army Integrated Training Program, the USDA Agricultural Research Service, and the U.S. Forest Service Rocky Mountain Research Station. Data collection was supported by the NSF's Long Term Ecological Research Program (sites including Jornada Basin, Konza Prairie Biological Station [Datasets - CSM04, CBP01, CGR02 and PVC02], North Temperate Lakes, and Sevilleta National Wildlife Refuges). We thank the following institutions for funding: NSF (DEB-0129298, DEB-0083422, DEB0245325, DEB-0080412, a Graduate Research Fellowship to EPW, and a Post-doctoral fellowship to PBA), and SBC-LTER (OCE99-82105).

\section{References}

Adler, P. B. 2004. Neutral models fail to reproduce observed species-time and species-area relationships in Kansas grasslands. - Ecology 85: 1265-1272.

Adler, P. B. and Lauenroth, W. K. 2003. The power of time: spatiotemporal scaling of species diversity. - Ecol. Lett. 6: 749-756.

Adler, P.B., E.P. White, W.K. Lauenroth, D.M. Kaufman, A. Rassweiler, and J.A. Rusak. In press. Evidence for a general species-time-area relationship. - Ecology.

Albertson, F. W. and Tomanek, G. W. 1965. Vegetation changes during a 30-year period in grassland communities near Hays, Kansas. - Ecology 46: 714-720.

Arrhenius, O. 1921. Species and area. - J. Ecol. 9: 95-99.

Bell, G. 2001. Ecology: Neutral Macroecology. - Science 293: 2413-2418.

Beven, G. 1976. Changes in breeding bird populations of an oak-wood on Bookham Common, Surrey, over twenty-seven years. - Lond. Nat. 55: 23-42.

Brooks, T. M., Pimm, S. L. and Collar, N. J. 1997. Deforestation predicts the number of threatened birds in insular southeast Asia. - Conservation Biology 11: 382-394.

Brown, J. H. 1998. The Desert Granivory Experiments at Portal. - In: Resetarits, W. J. J. and Bernardo, J. (eds.), Experimental Ecology. Oxford University Press, pp. 71-95. 
Burnham, K. P. and Anderson, D. R. 1998. Model selection and inference: a practical information-theoretic approach. - Springer.

Chalcraft, D. R., Williams, J. W., Smith, M. D. and Willig, M. R. 2004. Scale dependence in the relationship between species richness and productivity: the role of spatial and temporal turnover. - Ecology.

Chase, J. M. and Leibold, M. A. 2002. Spatial scale dictates the productivity-biodiversity relationship. - Nature 416: 427-430.

Clarke, A. and Lidgard, S. 2000. Spatial patterns of diversity in the sea: bryozoan species richness in the North Atlantic. - J. Anim. Ecol. 69: 799-814.

Coleman, B. D. 1981. On random placement and species-area relations. - Math. Biosci. 54: 191215.

Collins, S. 2000. Disturbance frequency and community stability in native tallgrass prairie. - Am. Nat. 155: 311-325.

Connell, J. H., Hughes, T. E., Wallace, C. C., Tanner, J. E., Harms, K. E. and Kerr, A. M. 2004. A long-term study of competition and diversity of corals. - Ecol. Monogr. 74: 179-210.

Connor, E. F. and McCoy, E. D. 1979. Statistics and biology of the species-area relationship. Am. Nat. 113: 791-833.

Diamond, J. M. 1969. Avifaunal equilibria and species turnover rates on the channel islands of california. - Proc. Natl. Acad. Sci. U. S. A. 64: 57-63.

Ellison, L. 1954. Subalpine vegetation of the Wasatch Plateau, Utah. - Ecol. Monogr. 24: 89-184.

Ernest, S. K., Brown, J. H. and Parmenter, R. R. 2000. Rodents, Plants, and Precipitation: Spatial and Temporal Dynamics of Consumers and Resources. - Oikos 88: 470-482.

Evans, E. W. 1988. Grasshopper (Insecta: Orthoptera: Acrididae) assemblages of tallgrass prairie: influences of fire frequency, topography, and vegetation. - Canadian Journal of Zoology 66: 1495-1501.

Grinnell, J. 1922. The role of the "accidental". - Auk 39: 373-380.

Gross, K. L., Willig, M. R., Gough, L., Inouye, R. and Cox, S. B. 2000. Patterns of species density and productivity at different spatial scales in herbaceous plant communities. Oikos 89: 417-427.

Hadly, E. A. and Maurer, B. A. 2001. Spatial and temporal patterns of species diversity in montane mammal communities of western North America. - Evol. Ecol. Res. 3: 477-486.

Harner, R. F. and Harper, K. T. 1976. The role of area, heterogeneity and favorability in plant species diversity of pinyon-juniper ecosystems. - Ecology 57: 1254-1263.

Harte, J., Kinzig, A. and Green, J. 1999. Self-Similarity in the Distribution and Abundance of Species. - Science 284: 334-336.

Harte, J. and Kinzig, A. P. 1997. On the implications of species-area relationships for endemism, spatial turnover, and food web patterns. - Oikos 80: 417-427.

He, F. L. and Legendre, P. 1996. On species-area relations. - American Naturalist 148: 719-737.

He, F. L. and Legendre, P. 2002. Species diversity patterns derived from species-area models. Ecology 83: 1185-1198.

Henderson, P. A. and Holmes, R. H. A. 1991. On the population-dynamics of dab, sole and flounder within Bridgwater bay in the lower Severn Estuary, England. - Netherlands Journal of Sea Research 27: 337-344.

Hubbell, S. P. 2001. The Unified Neutral Theory of Biodiversity and Biogeography. - Princeton University Press.

Inouye, R. S. 1998. Species-area curves and estimates of total species richness in an old-field 
chronosequence. - Plant Ecol. 137: 31-40.

Kaufman, D. M. 1998. The structure of mammalian faunas in the New World: from continents to communities. Biology. - University of New Mexico, p. 130.

Kaufman, D. M., Kaufman, G. A. and Kaufman, D. W. 2000. Faunal structure of small mammals in tallgrass prairie: an evaluation of richness and spatiotemporal nestedness. - In: Choate, J. R. (ed.), Reflections of a naturalist: papers honoring Professor Eugene D. Fleharty. Fort Hays Studies, Special Issue, 1:1-241., pp. 47-70.

Knapp, A. K., Briggs, J. M., Hartnett, D. C. and Collins, S. L. (eds.). 1998. Grassland dynamics: long-term ecological research in tallgrass prairie. - Oxford University Press, Inc.

Koleff, P., Gaston, K. and Lennon, J. 2003. Measuring beta diversity for presence-absence data. J. Anim. Ecol. 72: 367-382.

Lennon, J. J., Koleff, P., Greenwood, J. J. D. and Gaston, K. J. 2001. The geographical structure of British bird distributions: diversity, spatial turnover and scale. - J. Anim. Ecol. 70: 966-979.

Levin, S. A. 1992. The Problem of Pattern and Scale in Ecology. - Ecology 73: 1943-1967.

Lomolino, M. V. 2000. Ecology's most general, yet protean pattern: the species-area relationship. - Journal of Biogeography 27: 17-26.

Lyons, S. K. and Willig, M. R. 2002. Species richness, latitude, and scale-sensitivity. - Ecology 83: 47-58.

Magnuson, J. J. and Bowser, C. J. 1990. A network for long-term ecological research in the United-States. - Freshw. Biol. 23: 137-143.

McGill, B. 2003. Strong and weak tests of macroecological theory. - Oikos 102: 679-685.

McKale, W. and Young, W. D. 2000. Fort Riley: citadel of the frontier west. - Kansas State Historical Society.

McKinney, M. L. and Frederick, D. L. 1999. Species-time curves and population extremes: ecological patterns in the fossil record. - Evol. Ecol. Res. 1: 641-650.

Milne, B. T. 1992. Spatial aggregation and neutral models in fractal landscapes. - Am. Nat. 139: 32-57.

Myers, N., Mittermeier, R. A., Mittermeier, C. G., da Fonseca, G. A. B. and Kent, J. 2000. Biodiversity hotspots for conservation priorities. - Nature 403: 853-858.

Nelson, E. W. 1934. The influence of precipitation and grazing upon black grama grass range. USDA Technical Bulletin 409.

Ovaskainen, O. and Hanski, I. 2003. The species-area relationship derived from species-specific incidence functions. - Ecology Letters 6: 903-909.

Pigg, J., Coleman, M. S., Wright, J., Gibbs, R., Gido, K. and Lemmons, R. R. 1998. An ecological investigation of the ichthyofauna in the Deep Fork River, central Oklahoma: 1976 to 1996. - Proceedings of the Oklahoma Academy of Sciences 78: 67-110.

Pimm, S. L. and Askins, R. A. 1995. Forest losses predict bird extinctions in eastern northamerica. - Proc. Natl. Acad. Sci. U. S. A. 92: 9343-9347.

Plotkin, J. B., Chave, J. and Ashton, P. S. 2002. Cluster analysis of spatial patterns in Malaysian tree species. - The American Naturalist 160: 629-644.

Plotkin, J. B. and Muller-Landau, H. C. 2002. Sampling the species composition of a landscape. - Ecology 83: 3344-3356.

Plotkin, J. B., Potts, M. D., Leslie, N., Manokaran, N., LaFrankie, J. and Ashton, P. S. 2000. Species-area curves, spatial aggregation, and habitat specialization in tropical forests. - J. Theor. Biol. 207: 81-99. 
Preston, F. W. 1960. Time and space and the variation of species. - Ecology 41: 611-627.

Rahbek, C. and Graves, G. R. 2001. Multiscale assessment of patterns of avian species richness. - Proc. Natl. Acad. Sci. U. S. A. 98: 4534-4539.

Rosenzweig, M. L. 1995. Species Diversity in Space and Time. - Cambridge University Press.

Rosenzweig, M. L. 1998. Preston's ergodic conjecture: the accumulation of species in space and time. - In: Mckinney, M. L. and Drake, J. A. (eds.), Biodiversity Dynamics. Columbia University Press, pp. 311-348.

Russell, G. J. 1998. Turnover dynamics across ecological and geological scales. - In: Mckinney, M. L. and Drake, J. A. (eds.), Biodiversity Dynamics. Columbia University Press.

Russell, G. J., Diamond, J. M., Pimm, S. L. and Reed, T. M. 1995. A century of turnover: community dynamics at 3 timescales. - J. Anim. Ecol. 64: 628-641.

Sauer, J. R., Hines, J. E., Thomas, I., Fallon, J. and Gough, G. 2000. The North American Breeding Bird Survey, Results and Analysis 1966 - 1999. - USGS Patuxent Wildlife Research Center.

Scheiner, S. M., Cox, S. B., Willig, M., Mittelbach, G. G., Osenberg, C. and Kaspari, M. 2000. Species Richness; Species-Area Curves and Simpson's Paradox. - Evol. Ecol. Res. 2: 791-802.

Schiel, D. R., Steinbeck, J. R. and Foster, M. S. 2004. Ten years of induced ocean warming causes comprehensive changes in marine benthic communities. - Ecology 85: 1833-1839.

Shmida, A. and Wilson, M. V. 1985. Biological determinants of species-diversity. - J. Biogeogr. 12: $1-20$.

Sizling, A. and Storch, D. 2004. Power-law species-area relationships and self-similar species distributions within finite areas. - Ecol. Lett. 7: 60-68.

Stevens, R. and Willig, M. 2002. Geographical ecology at the community level: Perspectives on the diversity of new world bats. - Ecology 83: 545-560.

Veech, J. A. 2005. Analyzing patterns of species diversity as departures from random expectations. - Oikos 108: 149-155.

Veech, J. A., Crist, T. O. and Summerville, K. S. 2003. Intraspecific aggregation decreases local species diversity of arthropods. - Ecology 84: 3376-3383.

Venables, W. N. and Ripley, B. D. 1999. Modern Applied Statistics with S-PLUS. - Springer.

White, E. P. 2004. Two-phase species-time relationships in North American land birds. - Ecol. Lett. 7: 329-336.

Williams, C. B. 1964. Patterns in the Balance of Nature. - Academic Press.

Williamson, M. 1987. Are communities ever stable? - In: Gray, A. J., Crawley, M. J. and Edwards, P. J. (eds.), Colonization, Succession, and Stability. Blackwell Scientific Publications, pp. 353-371.

Willig, M. R., Kaufman, D. M. and Stevens, R. D. 2003. Latitudinal gradients of biodiversity: Pattern, process, scale, and synthesis. - Annual Review of Ecology Evolution and Systematics 34: 273-309.

Wissel, C. and Maier, B. 1992. A stochastic-model for the species-area relationship. - J. Biogeogr. 19: 355-362. 
Table 1. List of sites (and their 2 letter abbreviations) and taxonomic groups that were used to construct species-time relationships. See references and Appendix A for more detailed explanations of sampling methodology.

\begin{tabular}{|c|c|c|c|c|c|}
\hline Site & Taxonomic Group & Ecosystem & $\begin{array}{l}\text { Lat } \\
{ }^{\circ} \mathrm{N}\end{array}$ & $\begin{array}{l}\text { Long } \\
{ }^{\circ} \mathrm{W}\end{array}$ & References \\
\hline $\begin{array}{l}\text { North Temperate Lakes } \\
\text { LTER (NL) }\end{array}$ & fish, zooplankton & lake & $\sim 46.0$ & $\sim 89.4$ & (Magnuson and Bowser 1990) \\
\hline Oklahoma Streams (OK) & fish & stream & $\sim 35.1$ & $\sim 97.3$ & (Pigg, et al. 1998) \\
\hline $\begin{array}{l}\text { Great Basin Experimental } \\
\text { Range (GB) }\end{array}$ & plants & grassland & 35.3 & 111.5 & (Ellison 1954) \\
\hline Konza LTER (KZ) & $\begin{array}{l}\text { plants, grasshoppers*, } \\
\text { birds, mammals* }\end{array}$ & grassland & 39.1 & 96.6 & $\begin{array}{l}\text { (Evans 1988, Knapp, et al. } 1998, \\
\text { Collins } 2000, \text { Kaufman, et al. 2000) }\end{array}$ \\
\hline Hays (HY) & plants* & grassland & 38.8 & 99.3 & (Albertson and Tomanek 1965) \\
\hline Portal, AZ (PT) & mammals* & desert & 31.9 & 109.1 & (Brown 1998) \\
\hline Hinkley Pt. (HP) & fish* & marine & 51.2 & 3.1 & (Henderson and Holmes 1991) \\
\hline Eastern Wood (EW) & birds* & forest & 51.3 & 0.3 & (Beven 1976) \\
\hline Sevilleta LTER (SV) & mammals* & desert & 34.3 & 106.7 & (Ernest, et al. 2000) \\
\hline Jornada LTER (JN) & plants & desert & 32.6 & 106.7 & (Nelson 1934) \\
\hline Heron Island (HI) & algae, corals & reef & -23.4 & -151.9 & (Connell, et al. 2004) \\
\hline Diablo Canyon (UD, LD) & algae, invertebrates & intertidal & 35.2 & 120.9 & (Schiel, et al. 2004) \\
\hline Ft. Riley (FR) & birds* & grassland & 39.2 & 96.8 & (McKale and Young 2000) \\
\hline Breeding Bird Survey (BB) & birds* & -- & -- & -- & (Sauer, et al. 2000) \\
\hline
\end{tabular}

*denotes those groups that had suitable abundance data and were therefore used in the sampling analyses

$\sim$ indicates average across sites 


\section{Figure Legends}

Figure 1. Histogram of the pairwise difference between $r^{2} s$ of the power function and the logarithmic function models of the species-time relationship. Dashed line indicates the median difference, which is not significantly different from zero $(\mathrm{P}=0.65 ; 1$-sample sign test $)$.

Figure 2. Plot of the estimated probability density function for the transition points between sampling and ecological phases of the species-time relationship (STR). STRs are separated into three groups: Breeding Bird Survey of North America routes (BBS; solid line; data from White 2004), Fort Riley bird communities (FR; dotted line), and all other communities combined (dashed line). This was done in order to highlight the different behaviors of these three major groups. The density was estimated using standard kernel density estimation, with a normal kernel and a bandwidth of 0.74 (the optimal bandwidth for estimating normal densities for the 'all other communities' group). This technique produces results similar to those of a histogram using a default bin size, but these results are not sensitive to the placement of bin edges (Silverman 1986).

Figure 3. Comparison of the means (squares) and ranges (bars) of the exponents of the power function speciestime relationships for the different datasets grouped by taxa. Site identity within each taxonomic grouping is indicated by the two-letter abbreviation immediately above the maximum exponent bar and the abbreviations are listed in Table 1. Taxonomic abbreviations are as follows: FSH - fish, ZOO - zooplankton, PLT - plants, BRD - birds, INS - insects, MAM - mammals, COR - corals, ALG - algae, and INV - invertebrates. The dotted line within each taxonomic group indicates the average of the site means. The inset is the average and range of site-taxonomic group means grouped by ecosystem type (note the change in y-axis extent). Ecosystem type abbreviations are as follows: FR - forest, GR - grassland, DS - desert, MR - marine, IN - intertidal, RF reef, LK - lake, and ST - stream.

Figure 4. Relationships between mean annual species richness and the power function exponent of the speciestime relationship both within each site-taxa combination (main plot) and across the averages for each site-taxa combination (inset). Color and line style indicate taxonomic group (fish - solid blue, zooplankton - dashed blue, plants - solid green, birds - solid red, insects - dotted black, mammals - dashed red, corals - dashed black, algae - dashed green, and intertidal invertebrates - solid black). Site codes as shown in Table 1. Horizontal lines represent non-significant relationships $(\mathrm{P}>0.1)$. 


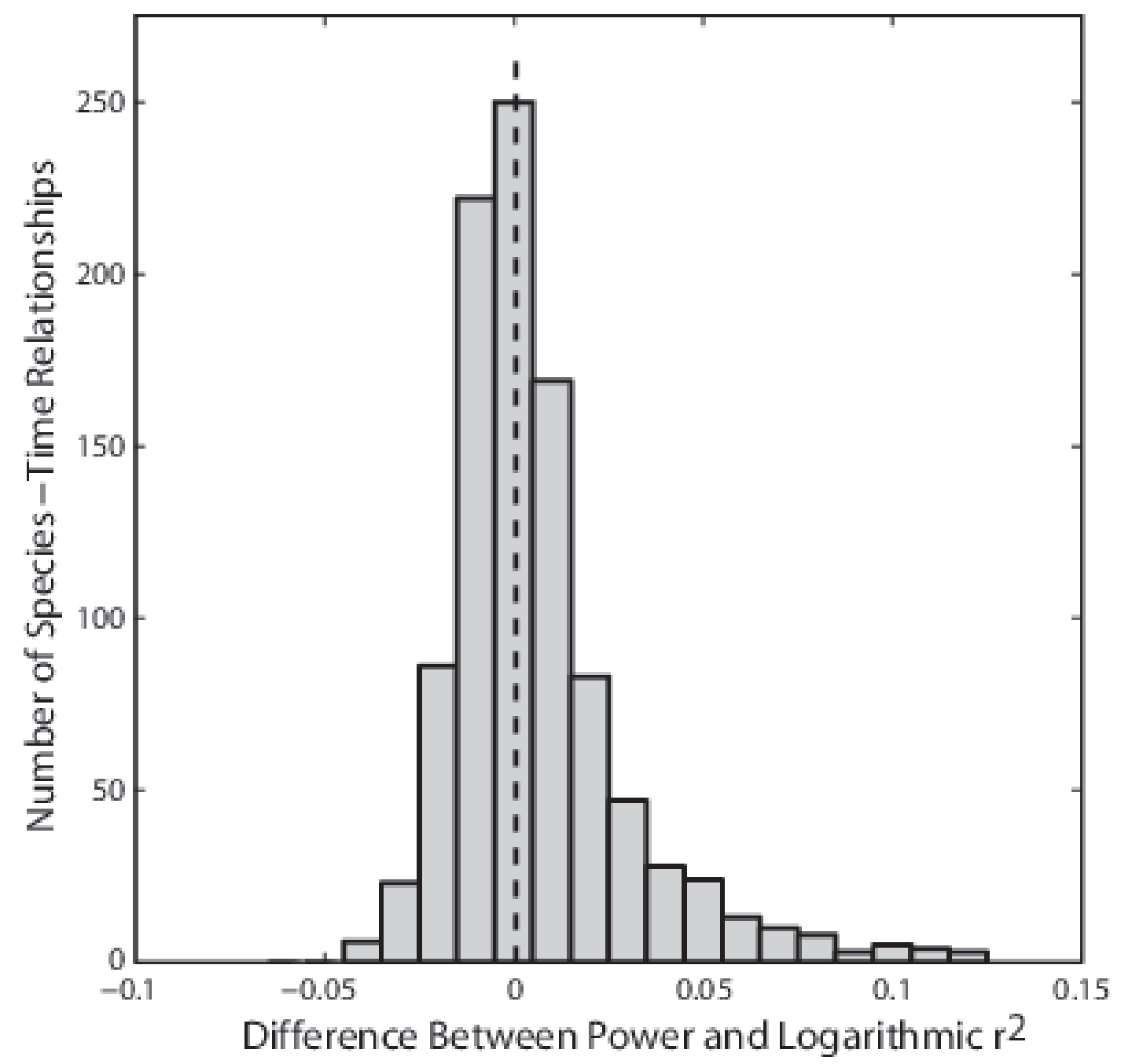




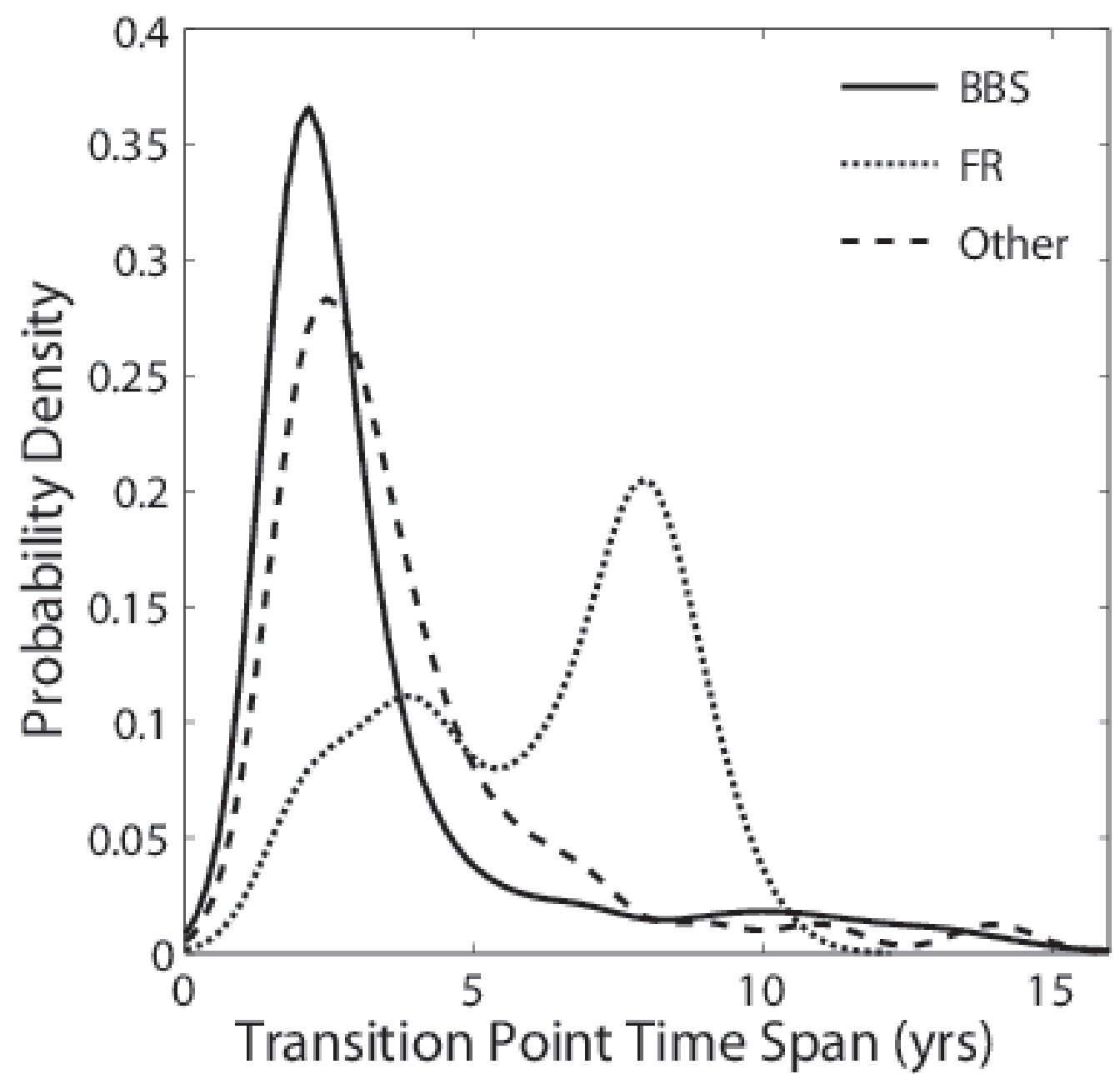




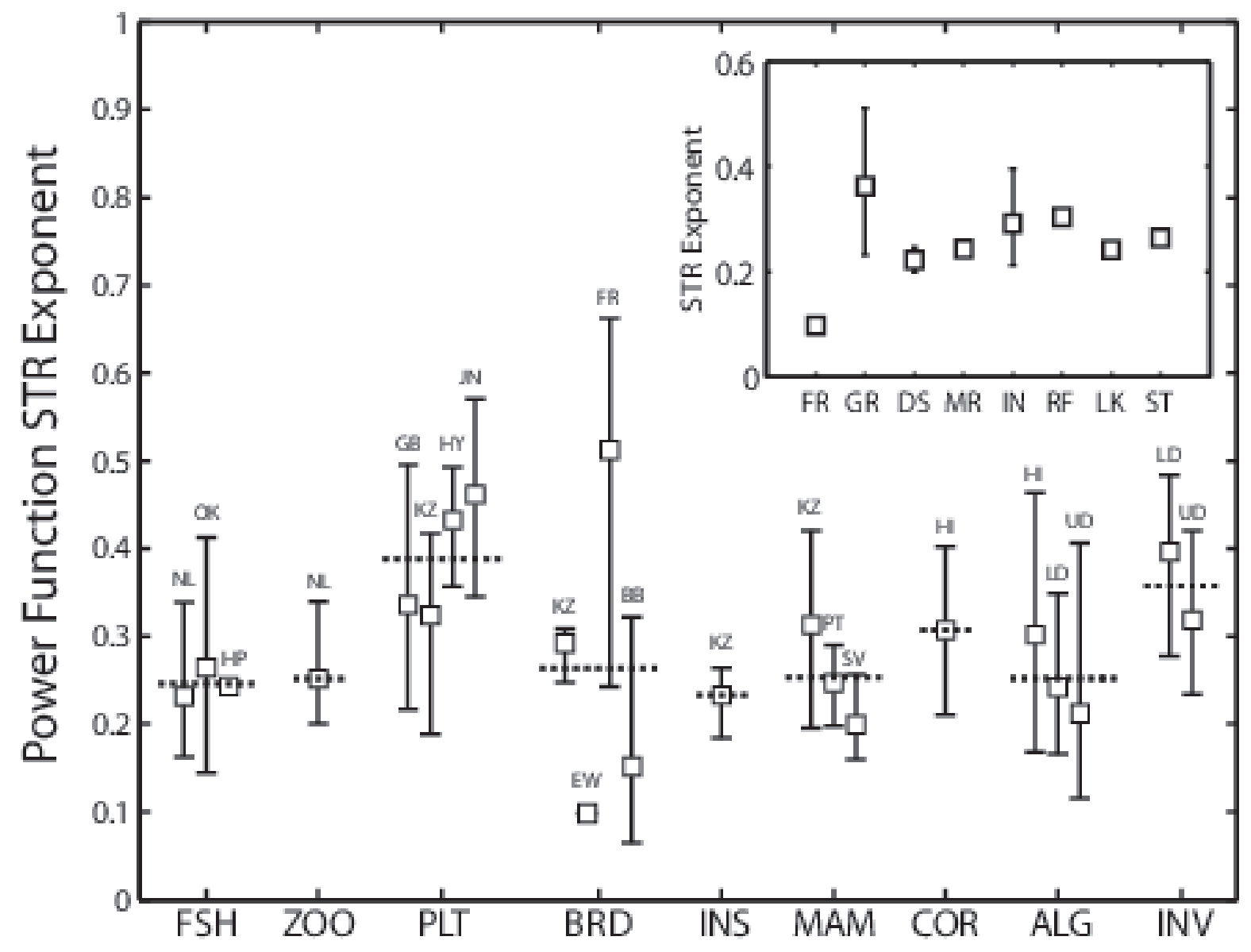




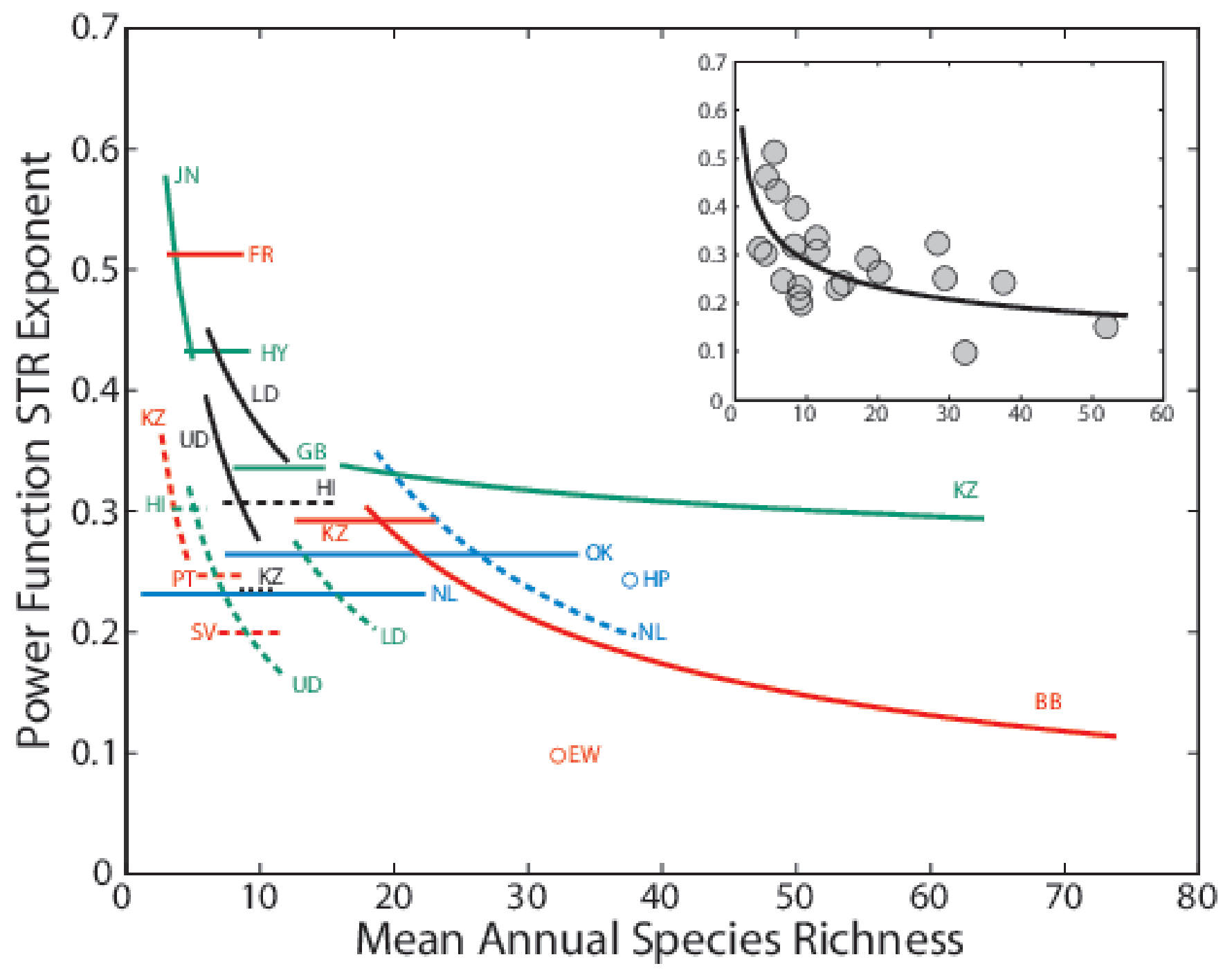

